\title{
Sharing customer data in the value chain
}

Received: 4th September, 2001

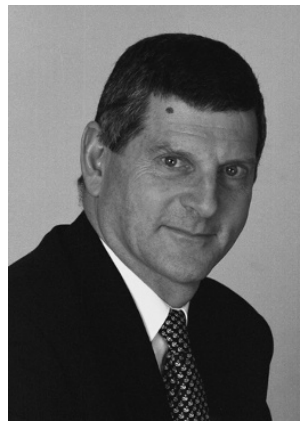

\section{Merlin Stone}

is IBM Professor of Relationship Marketing, Bristol Business School; Executive Consultant, IBM Business Innovation Services; Director, QCi Ltd., Swallow Information Systems Ltd. and Viewscast Ltd.

\section{Kevin Condron}

is Manager of B2B Solutions Marketing, EMEA for IBM (EMEA being Europe, Middle East and Africa). He was named marketing executive for IBM's Business-to-Business Solutions group, EMEA, in March, 2001. For four years prior to this appointment he was EMEA Marketing Manager for IBM's Business Intelligence solutions group. During this time Kevin headed up a marketing team that helped IBM grow to become a worldwide leader in the business intelligence market. He has over 11 years' experience with IBM and has been responsible for the marketing of a variety of products and services from management consulting to security software.

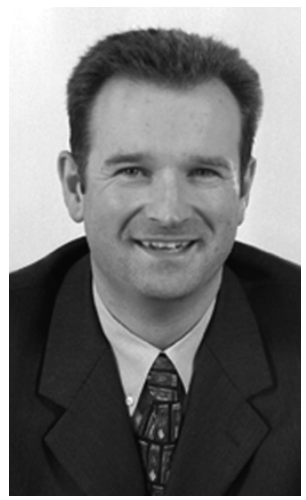

Abstract This paper discusses the issues involved in sharing customer data within the value chain, including reasons why companies should or should not share customer data, and the results of a survey on this question. It investigates whether companies really value their data, and companies' attitudes to sharing customer data. It also considers different approaches to sharing data, and the implications of sharing for businesses.

Professor Merlin Stone IBM UK Ltd., 76 Upper Ground, South Bank, London SE1 9PZ, UK. Mailpoint SEG1.

Tel: +44 (0)20 72025563 ; Fax: +44 (0)20 72025887 ; e-mail:

merlin_stone@uk.ibm.com

\section{INTRODUCTION}

Much of the focus of data-related discussions about value chain management is on how data about products and services (prices, availabilities etc.) can more easily flow up and down the supply chain using e-technology, helping customers towards the end of the chain serve themselves better. It is also clear, however, that the more suppliers further up the supply chain know about customers further down it, the better they can serve those customers' needs. Put simply, customer data are valuable to more than the supplier immediately facing the customer. An example of this is the willingness of suppliers in a market to share negative data about their customers, including those who do not pay or are fraudulent in their activities. While there are many such examples of negative (or risk avoidance) data being shared, there are very few occasions where positive data are shared within a market or value chain. In order to probe the subject of valuing and sharing data more deeply, the authors carried out two studies. The first was into the value of the customer database and the second was into attitudes to sharing data.

\section{VALUE OF THE CUSTOMER DATABASE}

The first study was a simple survey focusing on the extent to which companies valued their customer data. The logic of this part of the study was that in order to understand companies' attitudes towards sharing customer data, it was necessary to understand the extent to which they valued the customer data 
they already had. Of course, this is not a necessary connection. Companies can refuse to deal with other companies precisely because they do not know the value of these assets.

This study was conducted via e-mail with 250 supplier and client organisations. The client organisations were asked whether they formally valued their customer data, not necessarily for the purposes of valuation in their accounts, but at least for the purposes of making decisions about whether to invest further in acquiring or maintaining customer data.

\section{ATTITUDES TO SHARING DATA}

The second study was an in-depth qualitative study of nine major organisations and their attitudes to sharing customer knowledge with their value chain partners. The authors used as a research instrument a rather (too) long e-mail questionnaire, which they believe reduced the response rate. They can only excuse this because their study is the first significant attempt to research an issue in which they have been involved since their earliest work on the UK direct insurance industry. ${ }^{1}$ Therefore, these results are not presented as typical, but rather for what they are - how nine major companies view cooperation in the area of customer knowledge. This qualitative study, however, gives a clear view of what the main issues are in this area. These can now be researched by a quantitative study.

Before reviewing the results, it is sensible to review:

- the different ways in which companies can share customer knowledge

- the theoretical justifications for cooperating or refusing to cooperate in sharing customer knowledge
- the factors that influence why individual companies might or might not want to share customer knowledge with their business partners.

\section{RESEARCH ON THE VALUATION OF CUSTOMER DATA}

This research produced some results that the authors believe would be regarded as astonishing by most proponents of the idea of managing customers through data. It showed that almost no companies formally valued their customer data. Given the amount of investment dedicated to the building and maintaining of customer databases, as a medium that is an alternative to other ways of managing customers, this is surprising. In the authors' view, this is like building a marketing factory with no understanding of the rewards of doing so, or of the asset value thereby created.

The results are given in Table 1 . Forty-seven usable responses were received (a few other responses took the form of a discussion of the issues, but were not usable for this survey). This showed that most companies do not value their customer databases.

Particularly surprising was the number of specialist data analysis houses who said none of their clients did. How should these results be interpreted? Of course, formally valuing the stock of customer data so far accumulated is not a necessary condition for getting value from the data. The authors' understanding, however, is that while many companies can show that they can use data cost effectively to achieve results that contribute to the bottom line, it is rarely possible for companies to say whether creating (and maintaining) the data in the first place was worthwhile (whether or not it was!). 
Table 1: The value of data

\begin{tabular}{|c|c|c|c|c|c|}
\hline \multicolumn{2}{|c|}{ Company type ( $\mathrm{C}=$ client, $\mathrm{S}=$ supplier) } & \multirow[t]{2}{*}{ No } & \multirow[t]{2}{*}{ Yes } & \multirow[t]{2}{*}{ Don't know } & \multirow{2}{*}{$\begin{array}{l}\text { Can do calculations } \\
1\end{array}$} \\
\hline C & Charity & & & & \\
\hline C & Financial services & & & & 1 \\
\hline C & Mobile telephony service provider & & & & 1 \\
\hline C & Retail and travel services & & & & 1 \\
\hline C & Retailer & & & & 1 \\
\hline C & Consumer and business services & 1 & & & \\
\hline C & Consumer services & 1 & & & \\
\hline C & Logistics & 1 & & & \\
\hline C & Mobile telephony services provider & 1 & & & \\
\hline $\mathrm{C}$ & Travel & 1 & & & \\
\hline C & Automotive & 2 & & & \\
\hline C & Fast moving consumer goods & 2 & & & \\
\hline C & Petrol & 2 & & & \\
\hline C & Retailer & 2 & & & \\
\hline C & Financial services & 8 & & & \\
\hline $\mathrm{C}$ & Automotive & & 1 & & \\
\hline C & Financial services & & 1 & & \\
\hline C & Utility & & 1 & & \\
\hline C & Consumer services & & 2 & & \\
\hline C & Fast moving consumer goods & & 2 & & \\
\hline \multirow[t]{2}{*}{$\mathrm{C}$} & Publisher & & 2 & & \\
\hline & Total customers & 21 & 9 & & 5 \\
\hline S & Analysis house & & & 1 & \\
\hline S & Systems supplier & 1 & & 1 & \\
\hline $\mathrm{S}$ & Customer database bureau & 1 & & & \\
\hline S & Database bureau & 1 & & & \\
\hline S & Direct marketing consultant & 1 & & & \\
\hline S & Retail consultancy & 1 & & & \\
\hline S & University expert & 1 & & & \\
\hline \multirow[t]{3}{*}{ S } & Analysis house & 4 & & & \\
\hline & Total suppliers & 10 & & 2 & \\
\hline & Overall total & 31 & 9 & 2 & 5 \\
\hline
\end{tabular}

There are two ways of measuring the value of a customer database:

- the opportunity cost or alternative cost method

- the return on investment method.

\section{Opportunity cost method}

Here, the idea is that customer data are best valued by what it would have cost to achieve the same marketing results by other means. For example, a relevant calculation might be what it would cost through advertising, list rental and customer service to achieve a particular increase in contribution. In the authors' view, most companies do not have the data and systems required to support such a calculation.

\section{Return on investment method}

This requires calculating the full acquisition and maintenance cost of data, the full cost of using the data (eg customer contact costs), and setting it against the contribution achieved by using the data. The key question here is whether this should be done on an average or marginal cost basis. An economist's recommendation would be that the value is best measured on a marginal basis. For example, if another customer record were to be collected, what would it cost to do so, and what contribution would the company make from it. The benefit of this method is that whatever the actual historical cost of collecting the data, the data would be valued at replacement cost (the cost of collecting another name now) and 
current value (what use can be made of the record now).

This marginal return on investment method of valuing data would be most feasible, as many companies do know the marginal acquisition cost of data and the marginal benefit of using data. Applied to the whole database it would give some estimate of value. The problem here is to distinguish between an average and a marginal name. Clearly, a true marginal name cannot be used, as a company ought to have most names it wants already on its database. So it should look at the cost of acquiring a name that is of average value (ie average responsiveness, average resulting purchasing).

A short cut to this answer would be to look at the external price of data of equivalent quality. In some cases, where there is a ready market in customer data and most companies would use them to do the same thing (eg customer acquisition), this would be a good measure. But where the customer base is loyal to a particular supplier and represents the outcome of years of managing customers well, external valuation in this way would clearly be inappropriate.

\section{Conclusions on data sharing}

This is not the place to investigate database valuation models in detail. Most of the respondents did not do it either way! The practical implication of this is that if and when companies decide to share data, they are unlikely to have a solid financial basis for calculating the basis for any payments to be made, or indeed whether it is worth doing.

\section{WAYS OF SHARING CUSTOMER KNOWLEDGE}

The ways companies can share customer knowledge are influenced by:
- the type of data

- sharing process: eg level of detail, timing of transfer and access, hosting

- data protection legislation and industry conduct guidelines.

Each of these are considered in turn.

\section{Types of data}

These are the commonest types of data relating to customers likely to be of interest to partners:

- demographic and lifestyle data, including interests

— product preferences

- media preferences and responsiveness

- buying behaviour: transactions (what, where, how often etc.)

- complaints, merchandise returns, claims, risk management and exposures

— mode of payment

- use of loyalty scheme

- product data: inventories, orders of partner's customers

- product movements within the company

- promotional outcomes: redemptions, sales

- promotional plans, targets, performance and histories: what works, how well

- revenues and profits from customer relationship.

The authors' research shows that the closer they get to the purchases of individual consumers, the more reluctant companies are to share data. They seem to be much keener to share data such as demographic and lifestyle data, which can be gathered and sourced from trusted third parties. As knowledge of what customers buy, however, needs to be compared with what they could buy if the products and services were available 
to them, opportunities are being lost. It is as if each partner believes that they know best in this area.

\section{Sharing process}

The level of detail with which data are shared can be aggregated or at individual level, and sometimes a halfway house, with data made available in very small customer segments, or perhaps some made available at individual level, but with other data grouped. In general, the more detailed the transfer, the greater the perceived risk, although less risk is usually perceived when it comes to lifestyle and demographic data.

Timing of transfer (or access by one partner to another's data) can vary from on-line to batch. It seems that systems incompatibility can raise issues, although this may be an excuse.

Hosting may be by swapping ie each partner imports the other's data, partially or completely via a third party. Most respondents to the survey clearly felt comfortable with the role of a trusted third party.

Of course, the role of a third party is already well established in the data vending market, typically in the supply of lifestyle and similar data. These include:

- standard list rental, where the role of brokers as experts in managing data acquisition is well understood, eg selection criteria, data quality, control of contractual terms

- tagging of client databases by data suppliers: adding data to an existing customer or prospect file

- prospect pool supply: finding prospects that match a client's existing good customers, or in its negative form, identifying prospects to be avoided because they match a client's 'bad customer' profile
- one-off data pooling: assembly of an overall customer/prospect file from various client and external sources

- outsourced management of a customer or prospect file.

This description of the role of the third party, however, focuses on the operational procedures for bringing data together. Many clients have found that the involvement of an experienced third party brings benefits of a different order. Before investigating these, however, it is necessary to focus on the different skill and knowledge sets and capabilities that might be resident in a third party or with a client, and the types of companies that supply them. This is because the third parties are of many different types, with very different core skill sets. Each company, however, may have added to their core additional capabilities that can overlap with those supplied by other companies. Indeed, the market opportunity in customer management, combined with intense competitiveness, has led many companies to position themselves as generalised suppliers of customer management capabilities.

The main skills, knowledge and capabilities required for data-based customer management are:

— strategic analysis/planning/audit/ review of customer management activity

— strategic IT planning for customer management

- customer data analysis, for all purposes from understanding customer base to analysing results

- determining data requirements for customer management

- customer information management systems selection and implementation

- gathering consumer data from a non-transactional source, eg questionnaires, guarantee data 
- extracting customer information from client transactional sources

- campaign planning

- selection management

- media planning, including new media

- outbound communications management

— response handling and fulfilment.

These tend to be resident in the following types of company:

- data analysis houses

- lifestyle data suppliers

- list brokers

- database management bureaux

- direct marketing agencies

— response handling and fulfilment agencies

- IT hardware suppliers

— IT systems integrators

— software suppliers

- management consultancies

- client direct marketing departments (or similar), often including data exploitation staff

— client IT departments.

The important points to understand about the third parties are:

— the nature of their core skills/knowledge/capabilities

- their main business model(s), ie how they make their money, eg through sale of staff time, software, data access, service usage.

The main choice facing the client is the management advantage of reducing the number of suppliers, against the advantage of using the best of breed for each task. In some cases, however, this problem is dealt with by outsourcing customer management activities to one or more companies, leaving them to select partners for provision of specialist skills, knowledge or capability. Given the complexity of the above, many companies have realised that selecting suppliers to help in customer management is a critical decision, which should therefore be handled as a coordinated supplier selection process, rather than as a series of one-off decisions. The mistake many companies make, the authors' research has shown, is to assume that the choice of customer management system is the most important choice. Good systems working with poor data, processes and implementation programmes usually lead to very expensive ways of managing customers that do not please the finance director.

The practical implication of the above is that where a company is considering involving a third party in any area of customer management, and particularly where that involvement may lead to intense inter-working with other suppliers or to data cooperation with other peer companies, a key selection criterion should be a strong track record of working professionally and, usually quickly within a wider team.

\section{Data protection legislation and industry conduct guidelines}

Data protection standards have typically varied by country regulation and privacy expectations and culture. In some cases these are supplemented by the business conduct guidelines of an industry or market, for example in insurance and banking. More recently Europe has aligned its data protection legislation, this applies immediately to new business processes, systems and database developments, but has a delay time for existing systems to conform. Demand is increasing in some markets (eg USA) to tighten regulation which can protect individual privacy as data use and sharing become more prevalent. 
Rules of importance for value-chain management include:

- how the data were collected, for what purpose and with what expectation and approvals by the customer

- assured currency and relevance of the data

- data sharing within the company or group and with value chain partners

- retention of the data in identifiable or anonymous form

- customer data held in other forms (eg paper files).

Data protection legislation has become a key management issue for all new and existing processes and systems. A poor understanding of options can constrain a company's ability to use customer data competitively, while infringing legislation can have a dramatic and expensive impact on company brand, create legal actions and constrain future operations. To remain in control it is important to understand (and perhaps influence through recognised bodies) current and planned data protection legislation. Prioritised plans must be put in place to address these issues for each new and existing system or database.

\section{Arguments for sharing customer knowledge}

The main arguments for sharing customer knowledge include:

— improved targeting of marketing strategy

— improved targeting of marketing communications

— improved/more relevant content of marketing communications

— improved product planning

— improved pricing

- reduced costs of data acquisition
- reduced costs of data processing

- reduced media advertising

- reduced direct mail expenditure

- increased responsiveness to changing market conditions

- gaining an advantage over competition at the same level of the value chain

- bargaining more effectively with other value chain partners, (eg divide and rule)

- reducing market risk

— learning/skills transfer.

Survey respondents focused primarily on improved targeting, cost reduction and competitive advantage.

\section{Arguments against sharing customer knowledge}

The main arguments against sharing customer knowledge include:

- increased complexity of the marketing process

— increased marketing costs

— increased problems with data management

- conflict caused by mismatch in objectives/types/pace of marketing/ sales process

- general conflict of interest

- conflict of interest over customer ownership

— conflict of interest over data ownership

- temporary nature of some business relationships

— system incompatibilities

- legal complexities (regulatory, data protection)

- data security

— political difficulties

- skills shortage: data analysis

— skills shortage: data management

- accentuation of marketing skills difference between partners. 
Most of the research respondents stressed issues relating to lack of alignment skills, processes, systems. Conflict of interest was also raised.

\section{What influences sharing of customer knowledge}

The reasons for or against sharing data include the following.

\section{Sector-specific issues}

These may be regulatory, but can also be cultural, eg a history of conflict, or to do with the product, eg an intermittent purchasing cycle can give the retailer the upper hand because the supplier becomes more remote from the customer.

\section{Competitive situation}

This includes factors such as how many major companies are competing on each side of the market, their size distribution, their relative competitive strengths (eg products, distribution, branding). These factors tend to determine the risks if competitors get hold of information that has been shared. For example, if the customer list of a weak company gets into the hands of a strong company, then the latter will be in a good position to mount a competitive attack.

\section{Relative strengths and weaknesses of different partners}

This can apply to areas such as customer knowledge management or information technology - where sharing with a partner perceived to have a greater or lesser capability can lead to perceived risk of better/worse exploitation of data and consequent problems with customers or competitors. Skills and systems compatibility problems can have their origin here.
Particular marketing/sales approach of the different companies in the supply chain

This includes, in particular, the extent of use of targeted marketing. In many distribution chains, it is not uncommon for the level nearest the customer to be involved in direct marketing. This is changing, however, particularly as the economics of managing high volumes of customer data are not necessarily favourable to this approach.

\section{Perceived costs and benefits of sharing}

These are usually determined by the partners' views about the above factors. The research shows that there is little doubt about the general benefits - the issue is whether it pays the particular companies, and whether the partners can work with one another cost effectively.

\section{Availability of trusted independent intermediaries to help with process of sharing}

The research shows that third parties are generally trusted with demographic and lifestyle data, some of which may have been contributed or collected on behalf of specific partners. In financial services, this trust extends specifically to transaction data (eg credit cards).

\section{Relationship between prospective partners}

This includes strategic agreements to meet other objectives and, of course, trust.

\section{Research on data sharing: the case studies}

The sectors of the nine companies surveyed are given in Table 2. The detailed responses from these companies 
Table 2: Companies participating in data sharing research

National newspaper publishing

Automotive

Packaged consumer goods

Utility supply

Leisure retailing

Rail travel

Transportation and retailing services

Data for business and consumers

are not given, as this would compromise confidentiality. Therefore, only the main issues are highlighted.

\section{The utility company}

This utility company is a regional one, responsible for the marketing, customer administration and customer service for electricity, gas and fixed line telecommunications. Its business partners are, perhaps surprisingly, other utilities, as it may sell its electricity to be distributed through their networks, but it is also interested in partnership with directly competitive companies (ie those which also market energy rather than distributing it). Its marketing priorities can be summarised as increased targeting and search for more cost-effective distribution channels. Its attitude to the sharing of data is that it is not interested in selling data but more interested in strategic data exchange to meet effectiveness and efficiency objectives. It is particularly interested in exchange of data with direct competitors, as this helps in risk reduction. The main kind of data of interest here is payment practices of customers. This is an issue that the authors have explored in earlier researches. ${ }^{2-4}$ These researches focused on how bad customers could cause utilities problems by moving around leaving a trail of bad debt or late settlement. Because, however, of the conditions under which its data were collected (as a former area monopoly) it sees particular data protection problems in the legal area. It sees that increased data sharing might lead to problems due to different skills mixes in the sharing companies, as well as possible systems problems. The company considers itself well served in terms of the systems, analytical and reporting capabilities available to it, with a customer view of the data warehouse, campaign management systems etc. It is already matching data coming from a variety of electronic environments (Web, mobile) with its customer data.

\section{Packaged consumer goods company 1}

This company is a very large supplier of alcoholic drinks. Its business partners are specialist and generalist retailers. It maintains a strong focus on classic market-wide branding and marketing communication, but its focus on targeting and optimising the value of particular target customer segments is increasing. Its focus on Web activities and direct sales to consumers is also increasing, and it is expecting much increased communications activity through the Web and e-mail. It believes most of its data are of interest to retailers and vice versa. There is an expected imbalance in the areas of transactions and orders (where the retailers' data are of strong interest to the company). Some data exchange currently takes place, but there is a strong reliance on data from specialist third parties. The main perceived benefits of data exchange lie in improved competitive advantage, marketing planning and targeting, and reduced marketing costs. Systems incompatibilities and shortage of data management and analysis skills can, however, be a problem. Its systems and data management capabilities are good as far as batch analysis is concerned, but its ability to exploit this through on-line 
work with staff or customers is not strong. It has routine reporting for some area, but there is a weakness where sales and promotional response data are concerned.

\section{Packaged consumer goods company 2}

This company is a very large supplier of a broad range of packaged consumer goods, with its target market therefore being mostly women with families. Its business partners are retailers. It has its own customer database and is using it to achieve more targeted marketing, while maintaining a strong focus on product branding and retail distribution. It is particularly keen on areas such as optimising segment value and finding cost-effective direct channels of communication and distribution, and is also focusing on electronic channels particularly the Web, mobile and digital television. It is interested in data exchange in virtually all areas except product inventories. Again, strategic partnerships are a prerequisite for data exchange, and even here it would prefer to limit these to more data such as demographic and lifestyle data. This company is quite advanced in the types of analysis it performs on its data, such that its marketing decision makers are dedicating greater budgets to the direct channels that its database supports.

\section{Leisure services company}

This company is one of the UK's largest leisure retailing companies, but it also produces some of the products sold through its leisure outlets. Its partners are other producers of products. Its marketing focus is both across-the-board and targeted, with more targeted methods expected to increase. In terms of media, the biggest increases are expected in the area of Web, e-mail and mobile, followed by digital television. Where it comes to the company's interest in partners' data and its perceptions about its partners' interest in its data, the strongest focus is on leisure interests, product and media preferences, promotional responsiveness and purchasing data. In general, relatively few data are exchanged with partners, and there are strong concerns about confidential sales and promotional response data falling into competitive hands. Its willingness to exchange data is, however, increasing, though not in the area of transactions and responsiveness. Exchanging data in summary form is very acceptable, but again not about transactions or responses. Third party data are found to be useful, and willingness to share is much enhanced if the data are hosted by an independent third party. The benefits of exchanging data are seen to be mainly in the area of improved targeting, reduced marketing costs, reduced market risk and competitive advantage. Probable problems are in the area of poorly aligned marketing/sales processes, systems incompatibilities and skills. The company is well provided for when it comes to data warehousing, analysis and campaign management, but its reporting capability is incomplete.

\section{Travel and retailing services company}

This company supplies a variety of services to travellers, including retailing. Its business partners are providers of travel services and retailers who take space on its locations. Its marketing is therefore both general, in the sense of focusing on all customers in its target market, and targeted. It expects its use of e-mail, Web and mobile telephony to increase a lot, with digital television also 
increasing. Most kinds of data are of interest to it, and most of the data its partners have interest it. Transactions, demographic, preference and responsiveness data are of interest to it, as are product movements, orders, inventories and the like. Promotional, plans, performance and histories are also of high mutual interest, and these determine sales performance. The current situation on data sharing is mixed. Trust in relation to exchanging different types of data varies according to type of data, with in general less trust in the area of sales and response. Summary data is an area of stronger performance, where there is exchange. Being able to demonstrate improved profitability is the key to data sharing. Third-party demographics and lifestyle data are considered a valuable supplement to customer data. The benefits expected from data sharing are less than with other respondents, with less benefit of all kinds expected, but also fewer significant problems. The systems situation seems less complete, with only a few of the basic capabilities required for data exchange and subsequent professional use of the data in place. Much reporting is ad hoc rather than routine.

\section{Rail company}

This is a local rail company, which sells rail services and packaged holidays direct and through ticketing and travel agents. Its marketing approach combines general marketing to its whole customer base with an increasingly segmented approach. Its use of targeted media such as mail, e-mail and the Web is increasing, but not radically. Its interests in partner data and beliefs about its partners' interest in its own data are more or less evenly balanced. The exception to this is in the area of complaints, where it believes it would like to know more about its partners' data than it believes its partners would like to know about its data. In general, its preference is for data to be exchanged within strategic agreements. There is less trust in the area of exchanging transaction and response data than lifestyle and demographic data. Profitability and improved targeting are the main justifications for data exchange, particularly for data it might receive from its partners. Skills, systems incompatibilities and conflict over data and customer ownership are seen as barriers to exchange. Its systems, data analysis and reporting infrastructure is reasonably strong, except in the core area of the customer database.

\section{Automotive supplier}

This company supplies one of the premium automotive brands. Its key commercial focus is on cost-effective and more targeted distribution, but also more targeted product design. It is expecting to use more of all targeted channels of communication, particularly telephony of all kinds, digital television, and the Internet (e-mail and Web). Its business partners are car dealers, and it believes that its own data - all categories - are of interest to its partners, and their data — all categories - are of interest to it. Its partnership relationship with dealers is strong, and it exchanges data within strategic agreements with them.

Targetability and profitability are the key justifications for this data exchange. Systems incompatibility is, however, an issue for this company. In terms of technology, analysis and reporting, the company feels it is well provided for (eg data warehouse, campaign systems) with one area of weakness being in the bringing together of mobile and web-derived data with its existing sources of customer data. 


\section{National newspaper}

This company publishes one of the UK's main daily newspapers. Its intermediaries are newspaper distributors, particularly major wholesalers and retailers. Its marketing approach is broadly mass market, but the targeted element is growing. It is broadening the range of products and services marketed to its customers. In line with this, its media usage is broadening. It is increasing usage of the main direct media in selling to existing customers - particularly via direct mail, e-mail and the Web.

Purchasing, promotional responsiveness and customer service data owned by retailers is of particular interest to this company, relative to its perception of intermediaries' interest in its own data. Most other data it perceives to be of high mutual interest. Strategic agreements are necessary before this company would engage in data exchange, and it is reluctant to extend this to transaction and response data because of issues of trust. It does, however, buy data from its partners. It is happier with exchanging grouped data. It also believes third-party data sources are a valuable addition to its data. The main benefits of exchanging data it sees as improved targeting and responsiveness to market conditions rather than cost saving. Systems incompatibilities and differences in marketing skills are seen as particularly important barriers to data exchange. Its systems and data capabilities are reasonable but there are significant gaps, particularly in terms of on-line availability, which would make it difficult to engage in some aspects of data exchange.

\section{Data supplier for consumers and businesses}

This government-owned company sells its data in various forms - publications, digital supply — to organisations and individuals. Much of its output is sold through booksellers and newsagents, who are its business partners. Some of its major customers are utilities and telecommunications companies. Its marketing approach is both mass market and targeted. The main changes it sees to marketing methods are catalogue marketing and the use of the Web. It expects to be using more of most channels, including direct mail, ordinary telephony, digital television, e-mail and the Web. Most types of data are of interest to it. It believes that partners' interest in its data is mutual, with any imbalance being due to its retailers' ability to identify buying behaviour, promotional redemption and the like. In general the company is a recipient of data, but would be keen on full data sharing where profitability and targeting could be improved. Barriers to exchange include its own skill levels in analysing and managing data and systems incompatibilities. In the systems and business intelligence areas, it perceives it has significant weaknesses.

\section{SUMMARY OF TOPIC FINDINGS}

This study was a qualitative study. Yet the responses were on the whole consistent. They are as follows:

- in general, companies are happy to exchange data about general customer characteristics, but reluctant to do so about topics such as sales and promotional response

- where exchanging this kind of data, companies are likely to do so only in the context of a strategic agreement, backed by trust

- the role of third-party suppliers in supporting data exchange is important

- the main benefits of exchanging data were targeting, competitiveness and cost reduction

- the main barriers were perceived 
differences in analytical skills and, to some extent, process skills, plus perceived problems with systems incompatibility

- in one case, perceived legal barriers were important

- the quality of the respondents' systems and business intelligence capability varied significantly, with some claiming an ability to report in nearly all areas, with others admitting significant limitations.

\section{BUSINESS IMPLICATIONS}

The picture that emerges is a slightly confusing one. Behind it, the authors suspect there is uncertainty about the appropriate models of cooperation between suppliers and intermediaries in an increasingly digital age. There is hope, however. The questioning of retailer loyalty schemes is taking place at a time when product suppliers are becoming increasingly expert at understanding their markets, and reaching out more directly to consumers as this survey highlights. It shows that a sensible product supplier can look in a detached manner at whether it is really getting increased customer value out of the investments it makes in formal customer knowledge. The research into whether companies actually value their customer data has, however, produced some disturbing results. Although it is clear that getting value out of data does not depend upon valuing the data, it is also clear that lack of confidence in valuing the data indicates some vulnerability.

This was a relatively small study, though it is hoped it is evident to the reader that a lot of thinking has been going on - by authors and respondents. As nearly all the respondents saw data exchange as an important way to improve profitability, suppliers and intermediaries considering data cooperation should consider:

- which of their partners they can trust, or how risks can be contained

- which partners would be interested in strategic partnership

— what the possibilities are for joint customer management strategy

- where simple data cooperation is better than formal cooperation on customer management strategy

- how such a partnership might affect other aspects of marketing strategy: branding, product/service specification, pricing, distribution arrangements, marketing communication

- what enabling infrastructures (systems, data, processes, measures) are needed to provide their own capabilities and to support cooperative capability developments

- people implications: everything from joint decision making to training, and in its most advanced form, whether a cooperative organisation should be established

- the required implementation programme, including piloting and testing, to ensure that results are positive and that risk is controlled

- how third parties might help broker such an arrangement.

\section{Acknowledgment}

This paper was based on Chapter 6 of 'Successful Customer Relationship Marketing' by B. Foss and M. Stone, Kogan-Page 2001.

\section{References}

1 Stone, M., Foss, B. and Machtynger, L. (1997) 'The UK consumer direct insurance industry: A role model for relationship marketing?', Long Range Planning, Vol. 30, No. 3, pp. 353-363.

2 Stone, M. et al. (1997) 'Managing customer service in utilities', Close to the Customer Briefings, Policy Publications, December.

3 Stone, M. et al. (1998) 'Building customer-focused data', Close to the Customer Briefings, Policy Publications, November.

4 Stone, M. et al. (1999) 'Managing good and bad customers', Close to the Customer Briefings, Policy Publications, July. 